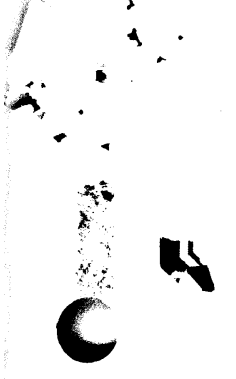

College of Agriculture and Home Economics THE OHIO STATE UNIVERSTTY

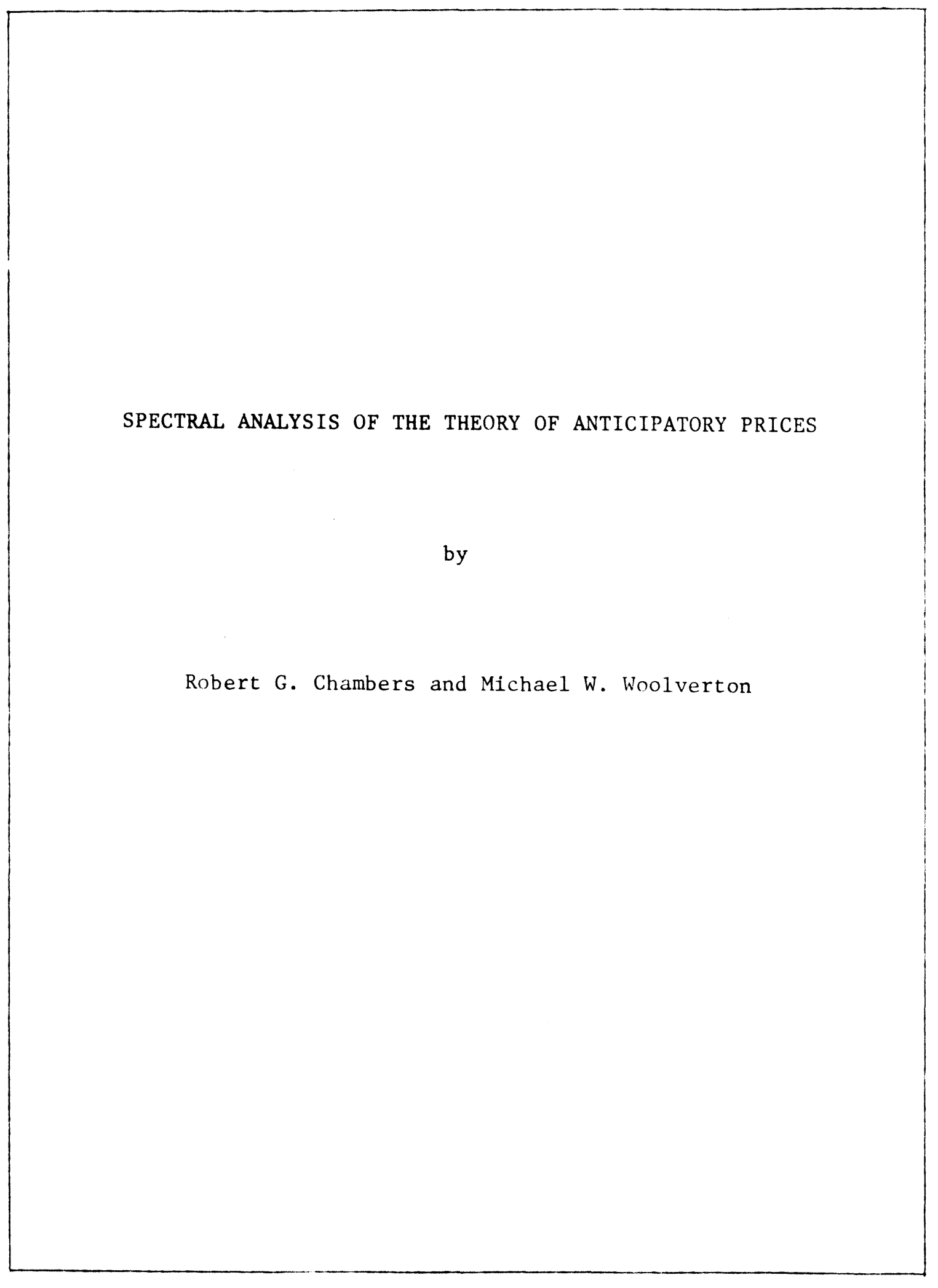

Department of Agricultural Economics and Rural Sociology Ohio Agricultural Research and Development Center August 1979 
Spectral Analysis of the Theory of Anticipatory Prices

One of the key contributions to the modern theory of intertemporal price relationships is Working's concept of the price af storage. The price of storage is defined as the difference between the current cash price and the price of a futures contract (or as the difference between the prices of two futures contracts with different dates of delivery). The concept tie price of storage in turn is pivotal to the understanding of the operation of modern futures markets for continuously storable conmodities. Given the centrality of this concept in the modern theory of intertemporal price behavior and the resurgence of interest in the operation and importance of futures markets, it appears that empirical investigation of the theory is merited. A series of excellent empirical studies including Brennan, Tomek and Gray and Weymar have tended to support Working's formulation of the price of storage concept. However, relatively little attention has been directed at intertemporal price relationships at the daily level and at the anticipatory price lypothesis that is a cornerstone of Working's price of storage concept.

This paper is an attempt to examine intertemporal price relationships at a dafly level by investigating the relationship between the cash and futures prices for three of the most important continuously storable commodities that are actively traded on modern futures markets--corn, wheat and soybeans. The techniques of spectral and cross-spectral analysis are used since they allow analysis of behavior in the frequency domain thus allowing easy identification of the cyclical behavior of the prices under investigation. This is particularly important since cross-spectral analysis 
enables one to examine the relationship between two time series at all relevant frequencies while the more standard regression analysis precludes this type of investigation.

In general, Working's anticipatory price hypothesis and its implications bear up well under empirical scrutiny in the wheat and corn markets. The soybean market, however, is a different story. Our results suggest that there is little if any relation between the behavior of the daily cash and futures price in the short run for that market. We draw several implications from this result in the following.

In the way of outlining what follows, we first examine the theory of anticipatory prices and its empirical implications. 'ie then proceed to outline the basic results of the theory of spectral analysis necessary to the paper and we then present the empirical results and interpret them.

\section{The Theory of Anticipatory Prices}

Prior to the formulation of the theory of the price of storage it was commonplace to view cash and futures prices as essentially independent prices. For example, it was widely held that events expected to intervene between the current date and the delivery date would not affect the cash price but would affect the futures price and thereby change the spread between the two prices. It was Working's contribution to recognize the key role storage plays in this price formation process by providing a continuous link between supply in the future period and the present supply situation. Working further points out that for continuously storable commodities any change in expectations is reflected in the entire array of prices. Hence, one can perceive a $\$ 4.00 \mathrm{fu}-$ tures price as, say, a $\$ 3.80$ cash price plus a market determined $\$ .20$ carrying charge; a positive carrying charge reflects relativly abundant storage. On the other hand, a negative spread between the cash and futures price re- 
flects a tight storage situation and not the expectation that the price $f$ the commodity will fall by the amount of the spread by the maturation of the contract.

How are prices formed" Working arues torcefull: for the conent of an anticipatory price, i.e., a price based on expectations. In iorling's view, prices are the result of interaction in the maretpace of various economic agents-each acting on the basis of his expectation of what the future holds. In the final view, therefore, price formation is based on an agglomeration of individual expectalions.

Working further eschews the traditional assumption that all individuals have equal knowledge in favor of the recognition that, "the amount of pertinent information potentially available to traders in most modern markets is far beyond what anyone can both acquire and use to good effect." Hence, different traders use different bits of information and signals in making their decisions. If this information comes onto the market in a random manner one would thus expect traders' actions and, therefore, prices to move in a fairly random manner. Yet, even though information is being accurately digested and utilized it is not necessary that prices fluctuate randomly, since, as Working recognizes, one of the most important sources of information for many, particularly short term, traders is how other traders act. For instance, it is well known that there exists a considerable body of traders trading on a "mechanical" basis. Trading in this fashion tends to smooth out price changes and make them appear less random than they might otherwise seem. Working's theory of anticipatory prices provides a rationale for both random walk price behavior as well as a low-order autoregressive process, and therefore, considerably predates Danthine's recent demonstration that efficient markets need not generate prices that fluctuate randomly. 


\section{Empirical Implications}

The empirical implications of the anticipatory price hypothesis are clear. First, because both the cash and the futures price reflect the same expectations, one expects a close relationship between changes in the cash price and changes in the price of futures contracts. To steal a phrase from Tomek and Gray, "... futures prices reflect essentially no prophecy that is not reflected in the cash price..." Given these considerations the theory implies that changes in cash and futures prices should be highly correlated. Second, the notion of an anticipatory price suggests that both futures and cash prices behave according to a random walk or a low order autoregressive stochastic process. In the parlance of spectral analysis, therefore, one would then expect to find a strong level of coherence at all frequencies and spectral densities that are consistent with efther a random walk or low order autoregressive stochastic process.

\section{Methods and Data}

To test the major hypotheses of the theoretical work by Working on intertemporal price behavior we concern ourselves mainly with statistics generated from the spectral density function and the cross spectral density functions which can be written respectively as

$$
f_{x}(\lambda)=\frac{1}{2 \pi} \stackrel{\sum}{k}=-\infty_{x}^{\infty} C_{x}(k) \exp -i \lambda k
$$

and

$$
f_{x y}(\lambda)=\frac{1}{2 \pi} \sum_{k=-\infty}^{\infty} C_{x y}(k) \exp -i \lambda k
$$


where $C_{x}(k)$ and $C_{x y}(k)$ are, respectively, the autocovariance function of $x$ and cross-covariance function between $x$ and $y$ of $l a g k$, is the angular frequency and $i=V-1$. There are various method of estimating the spectral density and cross spectral density functiona. Hower, in this study we employ the smoothed periodogram technique which generat es estimates of the spectral density function by averaging adjacent periodogram ordinated (for more details see Koopmans, Chapter 3 ). If the Daniell or rectanguiar weighting procedure is used then it can be shown that the stimated spertrat density function at frequency $\lambda_{j}$ is asymptotically distributed as

$$
\frac{f_{x}\left(\lambda_{j}\right)}{2 n} x_{2 n}^{2}
$$

where $\mathrm{n}$ is the number of periodogram ordinates averaged. A particularly important statistic for our purposes is the squared coherence,

$$
\rho_{x y}{ }^{2}(\lambda)=\frac{\left.f_{x y}(\lambda)\right|^{2}}{f_{x}(\lambda) f_{y}(\lambda)}
$$

which is clearly always between 0 and 1 . The squared coherence may be interpreted as the proportion of power at angular frequency $\backslash$ which can be explained by a linear regression of one time series on another. Hence, for heuristic purposes it $c$ an be treated much like the $\mathrm{R}^{2}$ statistic of a regression using data of only frequency $\lambda$. Therefore, a strong linear association between $x$ and $y$ at frequency $\lambda$ is to be associated with a $\rho^{2} x y$ approaching 1 , while weaker associations will generate a $d^{2}$ closer to zero. It can be demonstrated (Koopmans pp. 282-3) that the random variable

$$
\zeta=\tanh ^{-1}\left(\hat{\rho}_{x y}\right)
$$

is approximately normally distributed with mean and variance, $\tanh ^{-1}(0 \mathrm{xy})+$ $\left(\frac{1}{2}(n-1)\right)$ and $\frac{1}{2}(n-1)$ where $\hat{o}_{x y}$ is the estimated coherence and $\zeta$ is the inverse hyperbolic tangent of $\hat{\rho}_{x y}$. From this information we can generate approximate confidence intervals for the estimated coherence. 
Observations on day-to-day price changes were generated by 231 daily observations on the following: the closing price in dollars per bushel of the March, 1977, wheat and corn futures contracts and the January, 1977, soybean futures contract; the closing daily boxcar price for contract grade wheat, corn and soybeans at Chicago denominated in cents per bushel. Differencing, of course, leads to the loss of one observation so that the data used in the actual estimation procedure consisted of 230 observations.

\section{Estimation Results}

The most interesting aspect of the estimated spectral density functions is the remarkable similarity between the estimated spectral density functions for wheat cash price and futures price and the similarity between the corn cash and futures price spectral density functions. In both cases it looks as if one almost could lay the graph of the appropriate futures spectral density function directly on the plot of the spectral density function for the associated cash price.

Turning to the estimated spectra for the soybean cash and futures prices there is a surprisingly large disparity between these two statistics. The estimated spectral density function for soybean futures price exhibits a strong concentration of power at the relatively high frequencies suggesting very short term cyclical effects. Indeed, one is tempted to speculate that some of the concentration of power may be a result of the aliasing problem inherent in the spectral analysis of time series. That is, for daily observations it is impossible to detect a cycle of length shorter than two days. Concentrations of power at very high angular frequency may then suggest the presence of even shorter term cycles. Inspecting the spectral density function associated with the soybean cash price, one immediately notices the apparent lack of a concentration of power at any frequency. 
To further investigate the intertemporal characteristics of the day-today changes in the cash and futures prices cach estimated spectral densit:" was tested to sce if it was statistically consistent with a "white noise" or random-walk process. It can he shown that the theoretical spectral density Function of a randow-walk stwhastic process is $\frac{\sigma^{2}}{2 T}$ where 2 is the varince of the series. Therefore, by substituting a consistent estimate o: the variance of the respective series into this expression and using the result in (3) an asymptotic critical region for the nuli hypothesis of white noise can be constructed. Suppose that $\xi_{j}$ and $\delta_{j}$ are specified as the lower and upper limits, respectively, for the critical region of the $j$ th estimated spectral ordinate. If there are $r$ estimated ordinates it is straightforward to construct an $r$ dimensional rectangle

$$
R=\left[\hat{f}_{x}(\lambda): \xi_{j} \leq f_{x}\left(\lambda_{j}\right)<\delta_{j}, j=1,2, \ldots r\right]
$$

such that Prob $\left[\hat{f}_{x}(\lambda) \varepsilon R\right]=1-\alpha$. This rectangle is the $r$ dimensional joint confidence region for the $r$ spectral ordinates. Bonferroni's inequaity 1 / implies

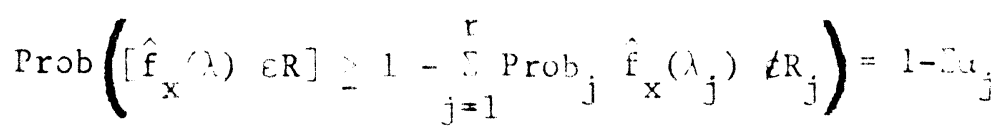

where $1-\alpha_{j}$ is the confidence coefficient for the $j^{\text {th }}$ interval. Using these results implies that if we choose $\alpha_{j}=\alpha / r$, we will have a joint confidence coefficient of $(1-\alpha)$. Applying this information to the white noise case where the theoretical spectrum is a constant defines a lover bound of $\xi=\frac{\hat{\sigma}^{2}}{4 n \pi} \times \frac{2}{2 n}\left(\alpha_{j}\right)$ and an upper bound of $\delta=\frac{\hat{\sigma}^{2}}{4 n \pi} \times \frac{2 n}{2 n}\left(1-\alpha_{j}\right)$. The null hypothesis is rejected if any estimated spectral ordinate falls outside the range defined by $\xi$ and $\delta$.

These results were used to construct asymptotic confidence regions at the .95 level for each of the estimated spectral density functions. The 
confidence regions are reported on Figures $1-6$. With the sole exception of the estimated spectral density function for soybeans futures price change all the estimated spectral density functions do not appear to be statistically inconsistent with the null hypothesis of a random walk process. Again, however, one must be struck by the divergence between the estimated spectral density functions for soybean cash price change and soybean futures price change. The former is clearly consistent with a random-walk process, while the latter is not and rather seems to be consistent with some type of low order autoregressive process. In any case, the futures price is clearly noisfer at high frequencies than the cash price suggesting greater short run variation. More will be said about the implications of this result later. To more closely investigate the relationship between the various prices, the cross spectral density functions for each respective pair of cash and futures price were calculated using the smoothed periodogram technique. In turn, the coherence statistic assoctated with each pair was calculated over the frequency 0 to $\pi$; the results of the latter are plotted in Figures $7-9$. Using the result in (4) establishes a critical value of approximately .45 at the .05 confidence level for the test of the null hypothesis $\rho=0$ against the alternative hypothesis $\rho>0$. Hence, any estimated coherence that is less than .45 cannot be said to be statistically significantly different from zero.

Interestingly, the coherence as estimated at all frequencies for the corn and wheat price couples are all greater than the critical level and in their case the null hypothesis of $\rho=0$ cannot be accepted. However, in the case of the estimated coherence between the soybean spot and cash price by far and away the majority of the coordinates are below the .45 level and, therefore, cannot be declared statistically significantly different from 
zero. The only estimated coherencies that are above the .45 level are, in the main, associated with angular frequencies smaller than . 8 . Hence, any strong degree of relationship between the moventents in soybean cash and futures prices seems to be restricted to cycle lengths of more than seven days--in terms of daily data--the relat vely iong run. There seems io be little evidence of a linear reldituship on a day-to-day basis.

\section{Implications and Conclusions}

Clearly, the results reported above do nct offer unqualified supfor:

for the anticipatory theory of price changes. Although, price changes in the wheat and corn market appear to be very consistent with the theory, this is not the case for soybean cash and futures price changes. Particularly, there is little or no evidence of any close relationship between cash and futures price changes at the relatively high angular frequencies (short cycle lengths) suggesting that short run price movements in the cash and futures market are not closely related. Further, analysis of the estimated spectral density functions for soybean cash and futures price changes indicates a much higher concentration of power at high frequency levels for futures price changes than for cash price changes. Presumably, therefore, there is much more day-to-day fluctuation in the futures market than in the cash market. However, there does appear to be a close relationship in the long run between soybean cash and futures price changes as evidenced by the relatively high coherencies observed at low angular frequencies.

Hence, one may presume that, in the short run at least, cash and future prices in the soybean market reflect different sets of expectations or at least different decision rules. If this supposition is true then it is necessary to discover why the soybean market operates in an inherently different manner than the markets for the other storable commodities under 
investigation. We feel that the explanation lies in the structure of the soybean futures market.

The soybean futures has been relatively more attractive than the corn and wheat markets to a class of speculators which include scalpers, day traders and non-member position traders. These speculators lack or are late acquirers of market information, hence they tend to trade intuitively or mechanically hoping that small price movements will be sustained. Such trading may well account for the apparent autoregressive structure of the soybean futures price spectral density function. Although the activities of these traders cause soybean futures markets to be very noisy in the short run, they have little effect on the cash market soybean price since the difficulties of ownership exchange and arranging for the transfer of the physical commodity prohibits similar short term switches in position in the cash market for saybeans. Hence, the relatively low estimated coherence for the higher frequencies. However, in the longer run (lower frequencies) there appears to be a much closer relationship between changes in soybean cash and futures prices.

One explanation of this phenomenon may lie in the trading behavior of speculators in the market for soybean futures contracts. As this class of speculators becomes more well informed and closes out losing speculative positions, the soybean futures market price comes to more closely reflect underlying expectations that are based on accurate interpretation of existing market conditions and becomes more correlated with the cash price of soybeans. Therefore, in the lorg run one would expect a much closer relationship (as observed) between cash and futures price behavior. 
The soybean futures market is also characterized by the unusual degree of spreading activity on the part of speculators (see e.g. Hammonds). Although, theoretically, the difference between two futures prices can be conceptualized in the same manner as the difference between the cash and a futures prices in terms of the price of storage, it should be clear that wide scale spreading coupled with mechanical trading could very well drive a wedge between cash and futures price behavior in the short run. This is especially true since spreading is undertaken solely with reference to differences between the prices of futures of contracts with different delivery dates and without reference to the cash market. However, as time wears on one would expect accurate digestion of information to insure that this dichotomy be removed.

Apparently, therefore, the soybean market has a high concentration of "... traders with a low level of trading competence" (Working) and spreaders. Hence, the "corrective power of the market" tends to take a longer time to fully develop. In other words, there are substantial short term price effects in the soybean futures market that are directly attributable to these mechanical and intuitive traders. It appears that in the long run the expectations of the relatively better informed traders tends to dominate--witness the very high levels of coherence at high angular frequencies. Further empirical investigation and theorizing is needed to determine if a restatement or alteration of theory of anticipatory prices is necessary. 
Figure 1: Spectral Density Wheat Cash Price Change

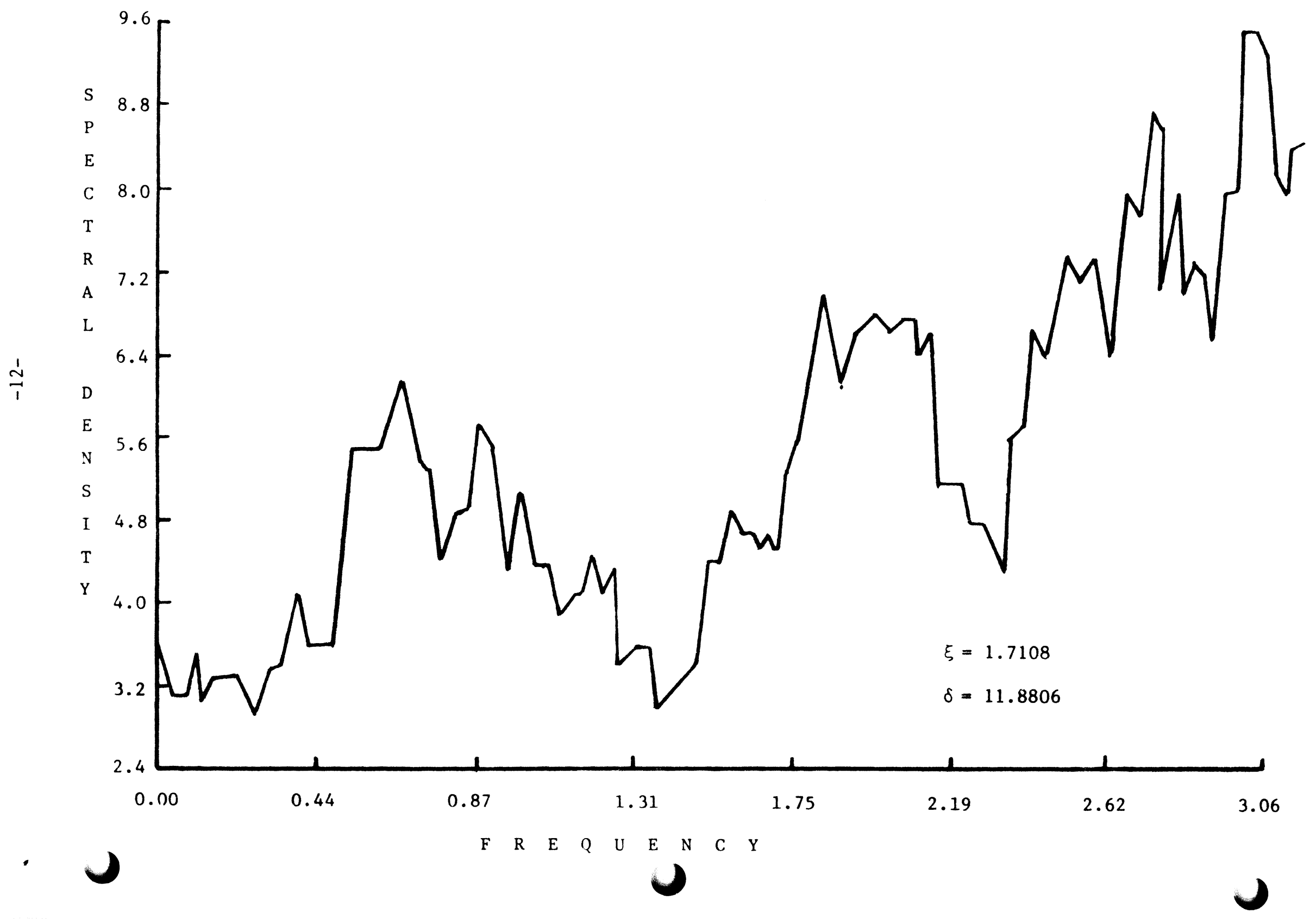


Figure 2: Spectral Density Wheat Futures Price Change

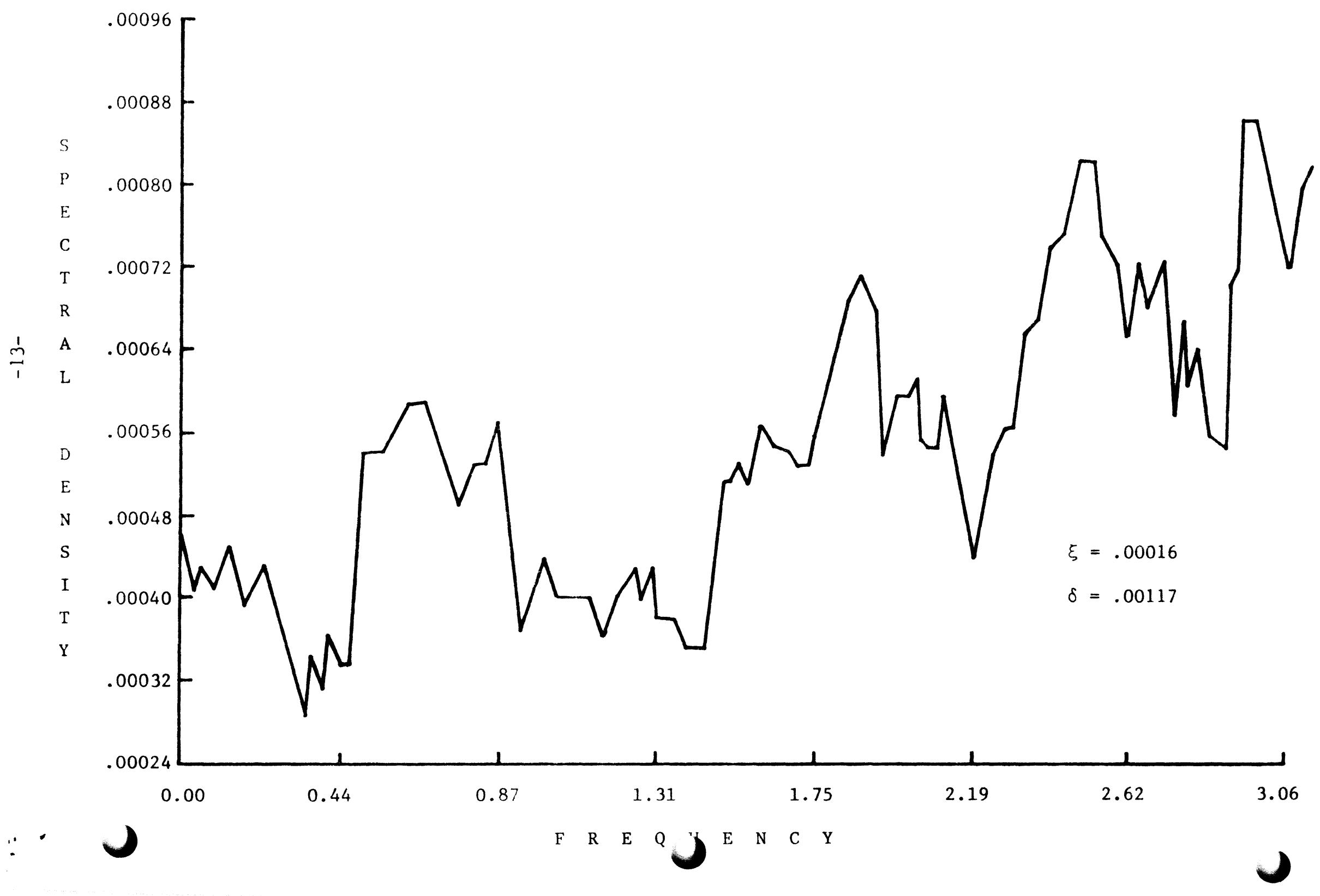


Figure 3: Spectral Density Corn Cash Price Change

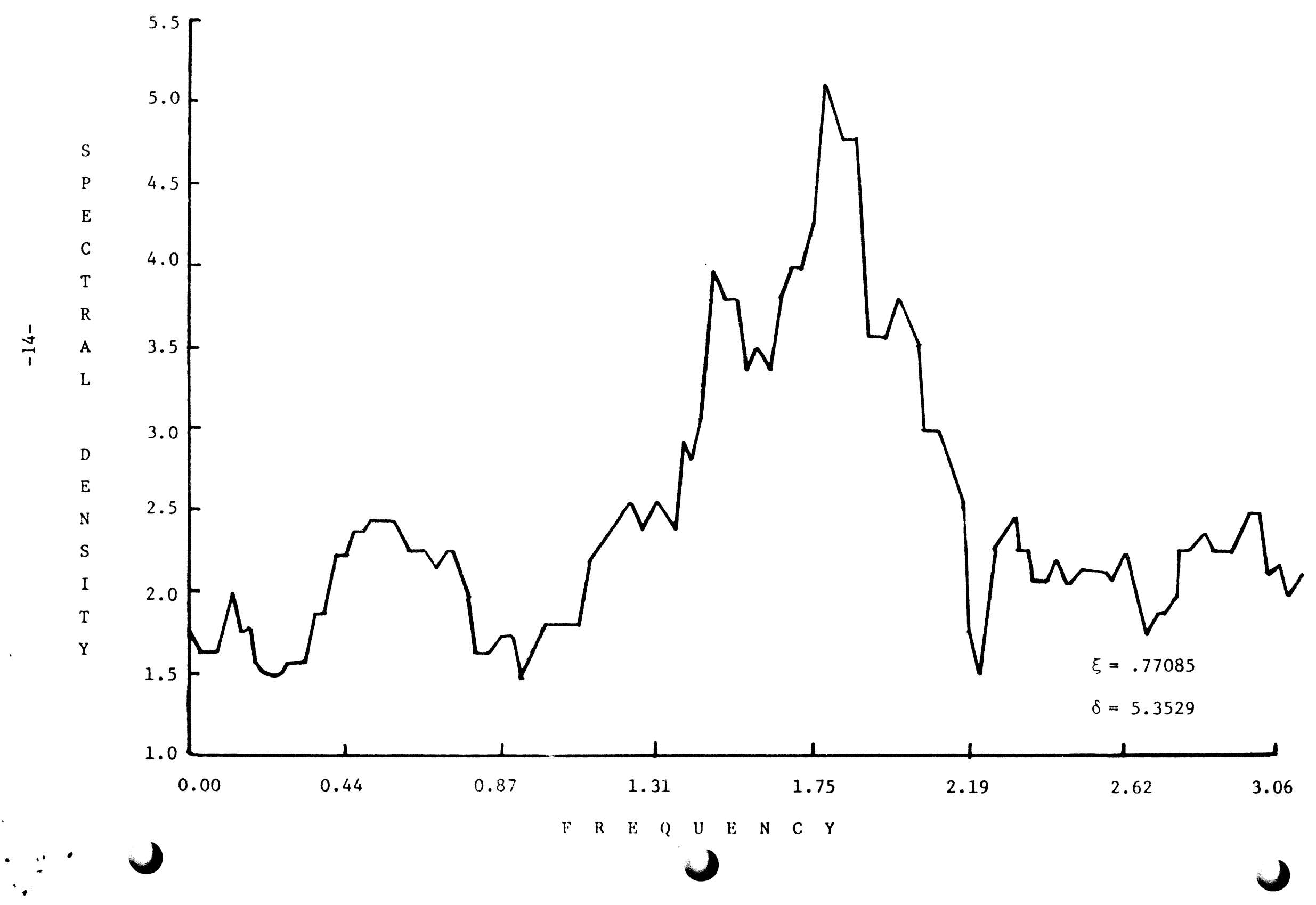


Figure 4: Spectral Density Corn Futures Price Change

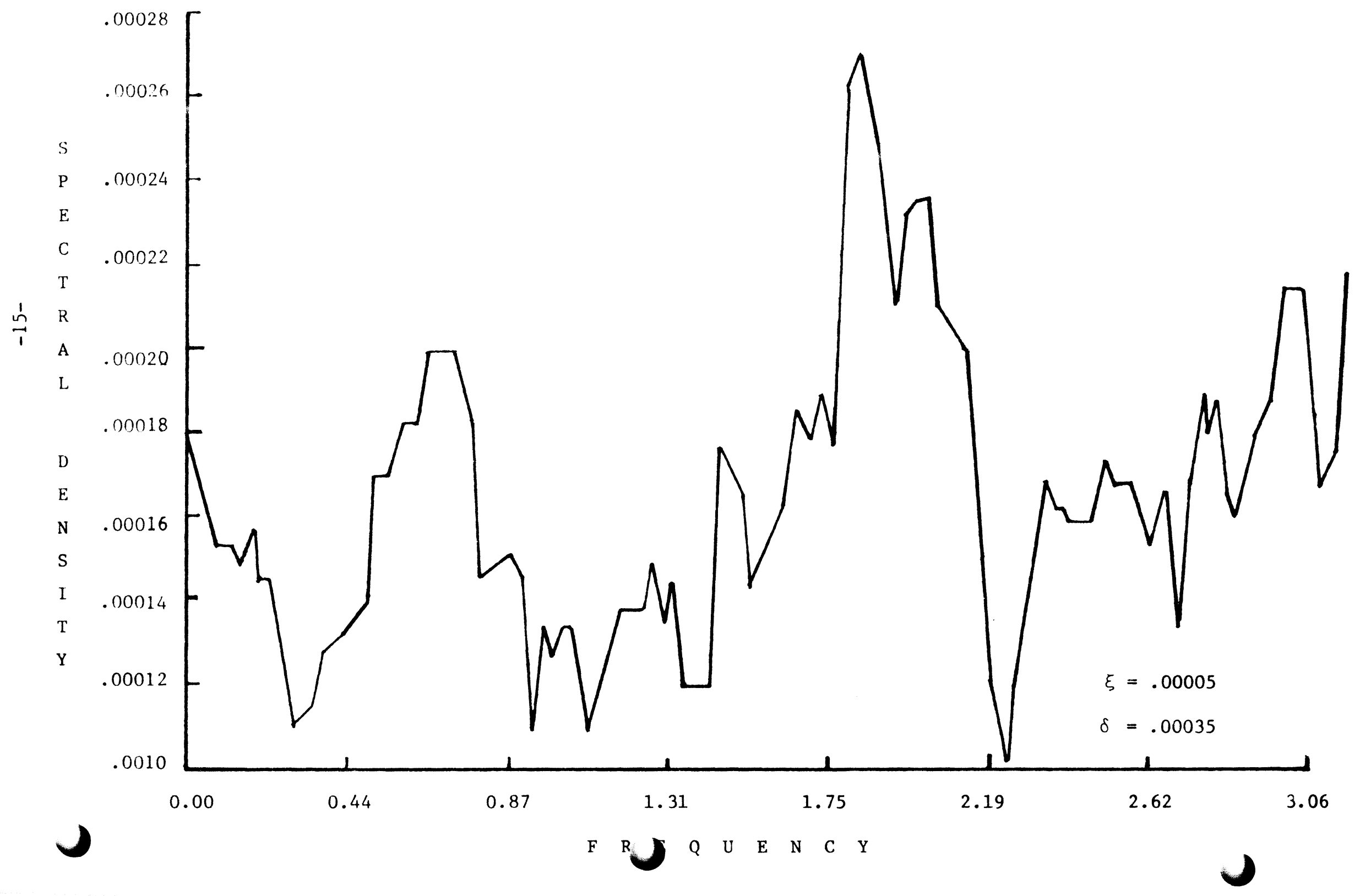


Figure 5: Spectral Density Soybean Cash Price Change

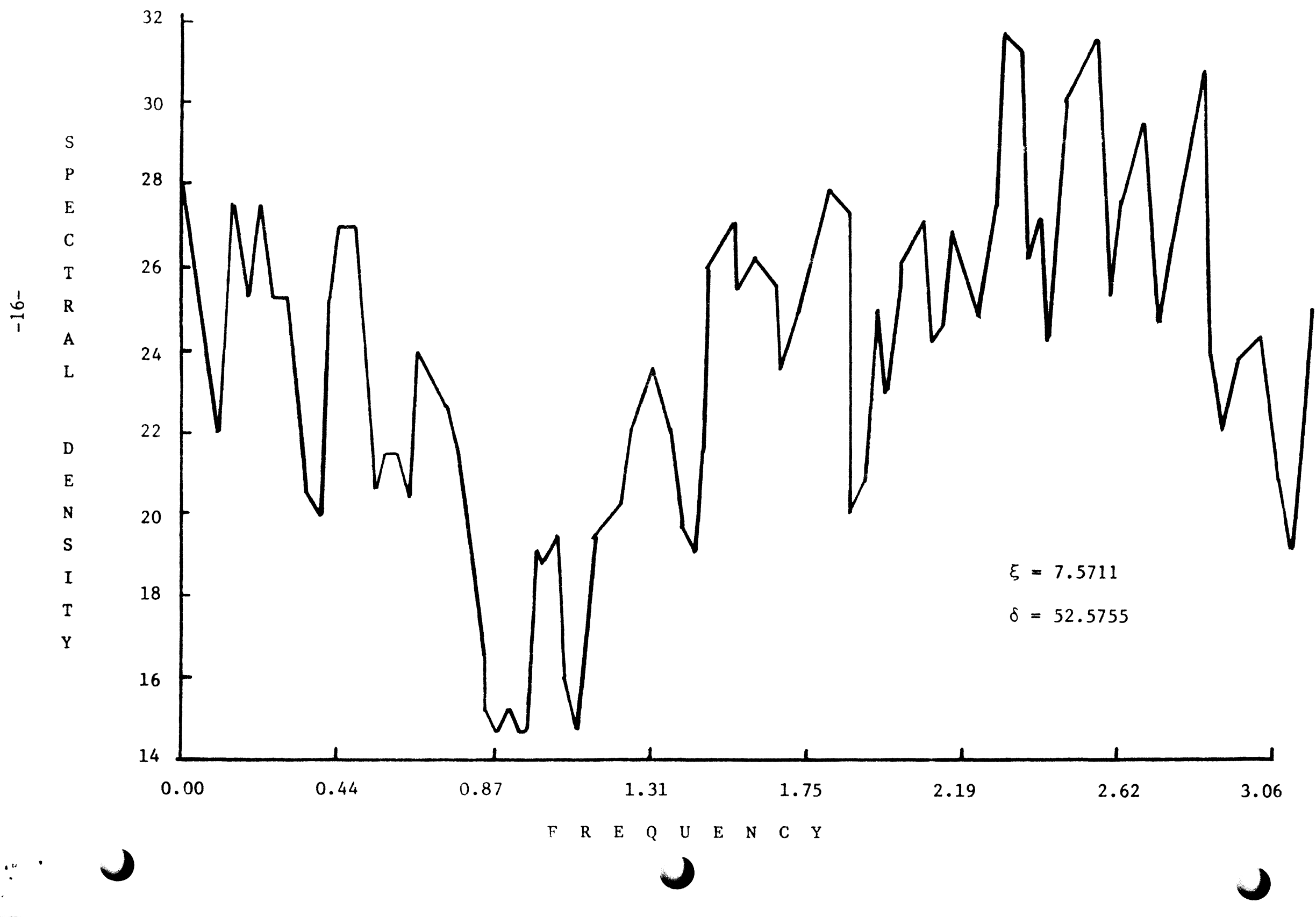


Figure 6: Spectral Density Soybean Futures Price Change

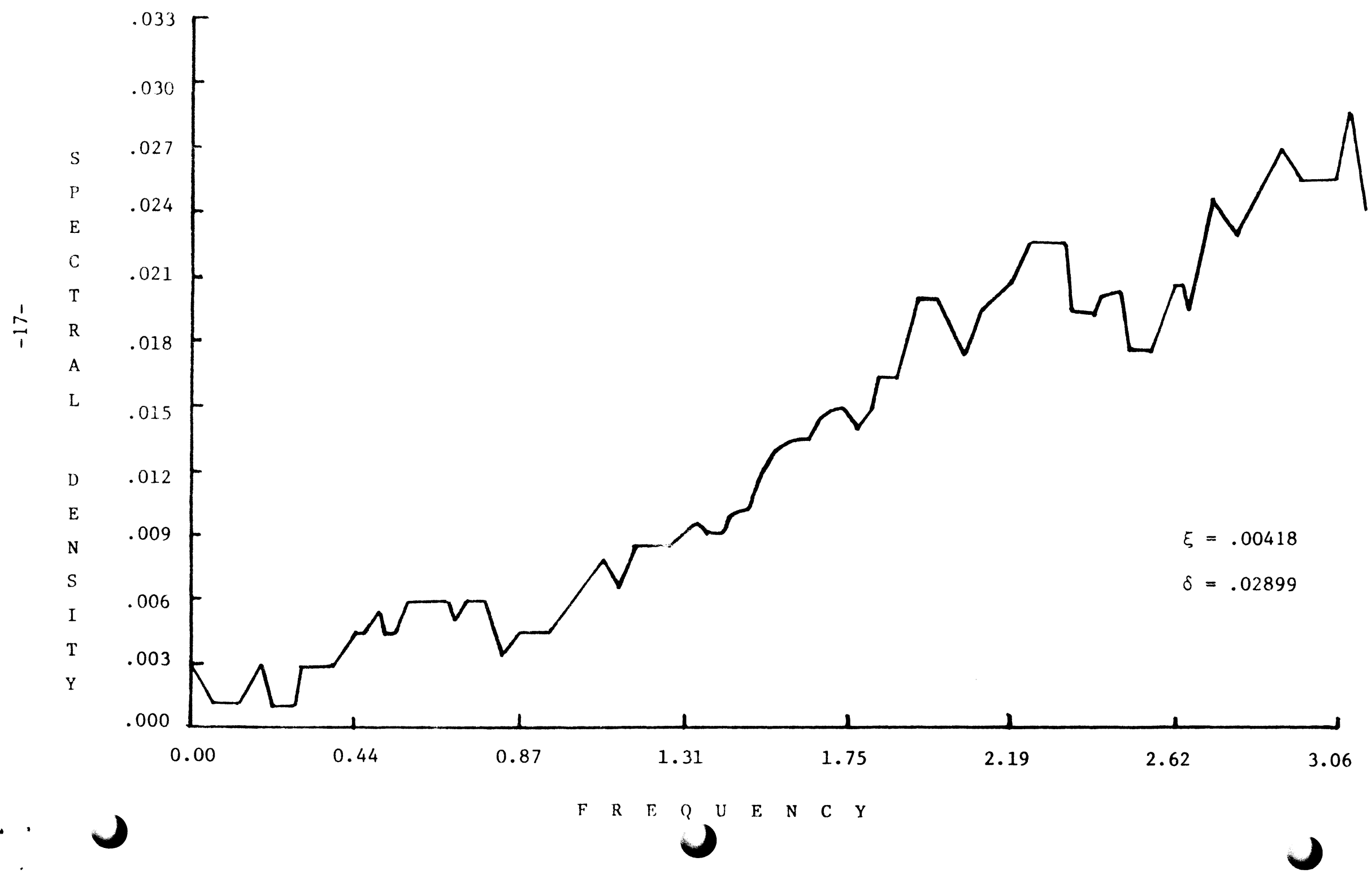




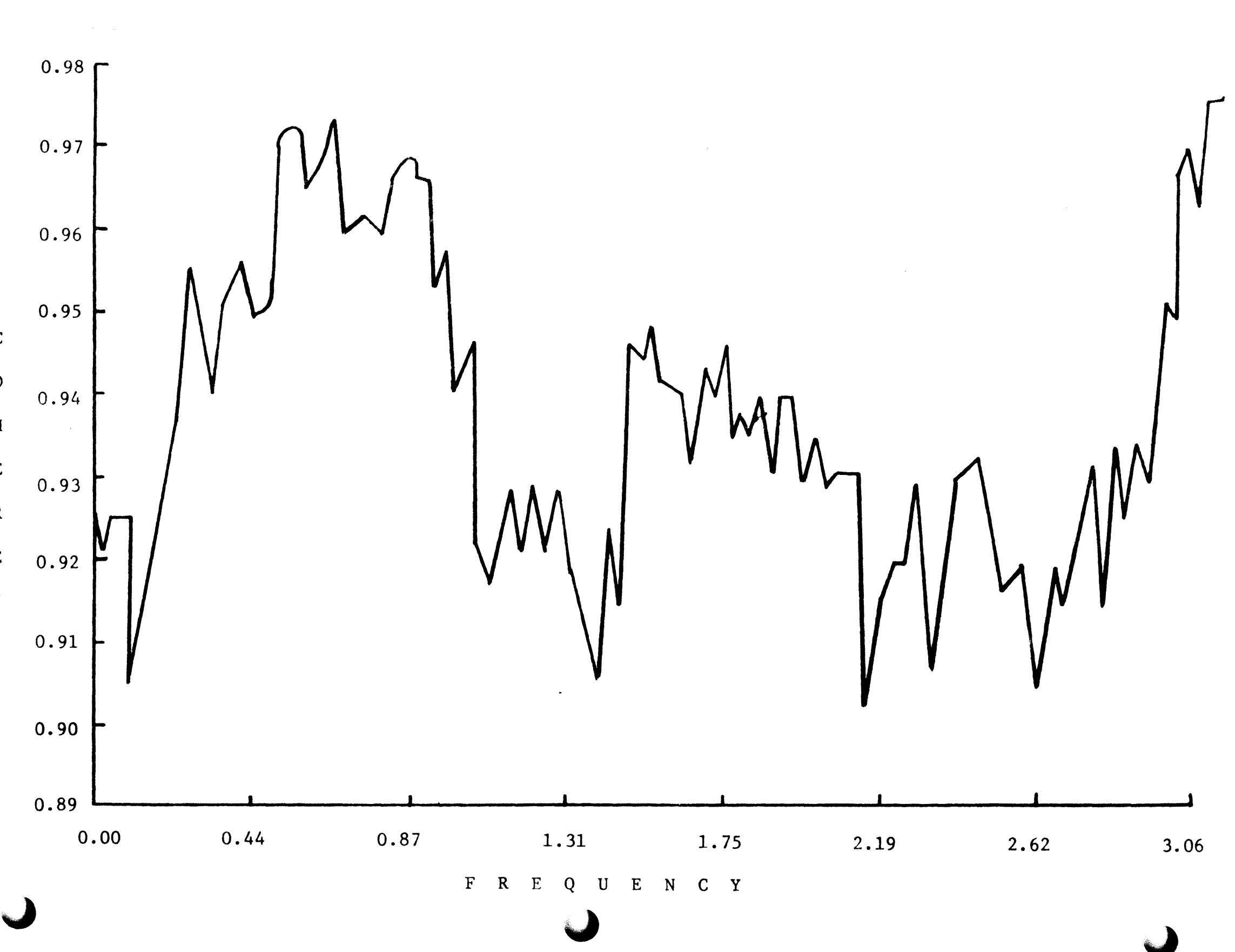


Figure 8: Coherence Corn Futures, Cash Price Changes

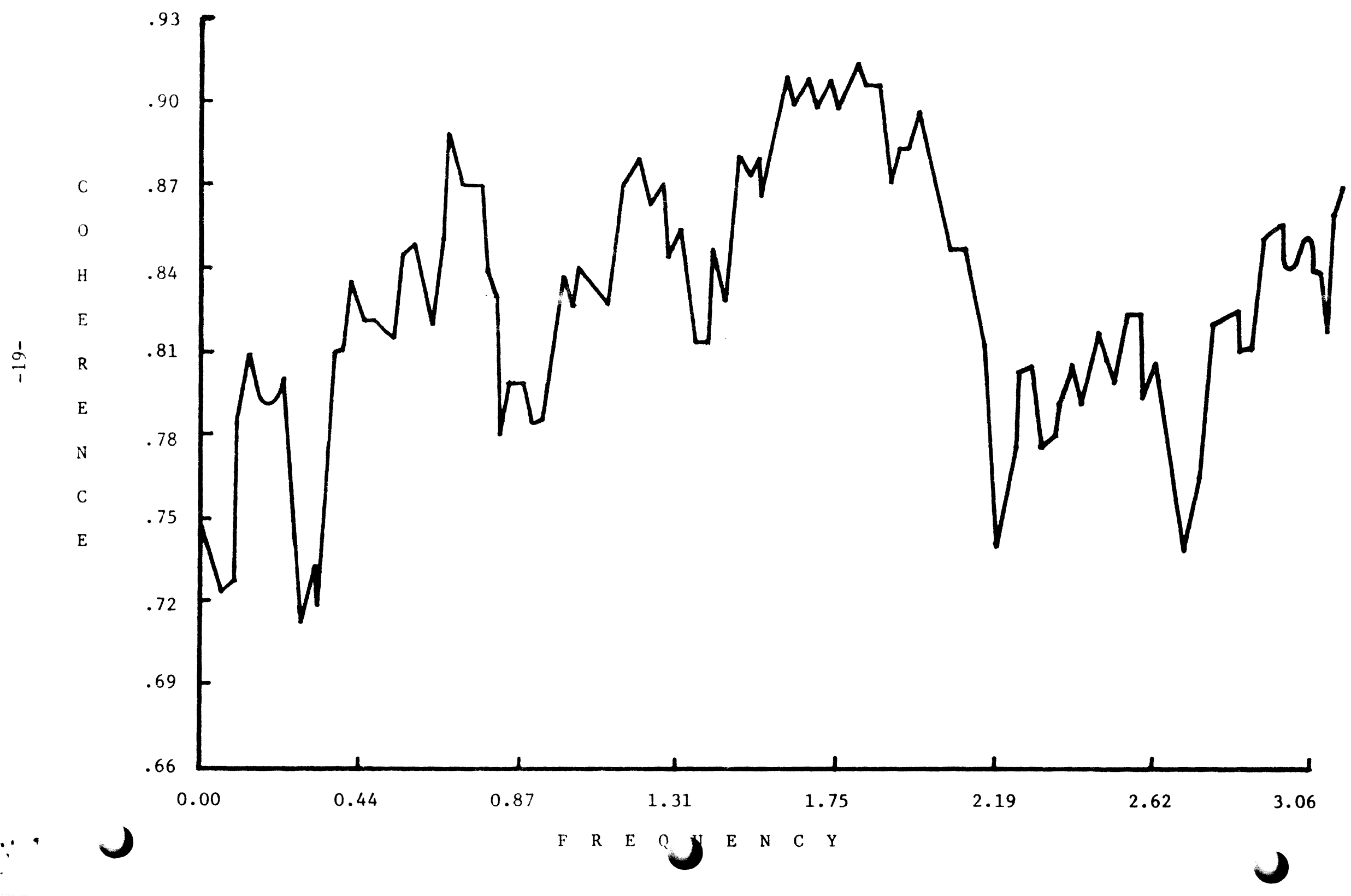


Figure 9: Coherence Soybean Futures, Cash Price Changes

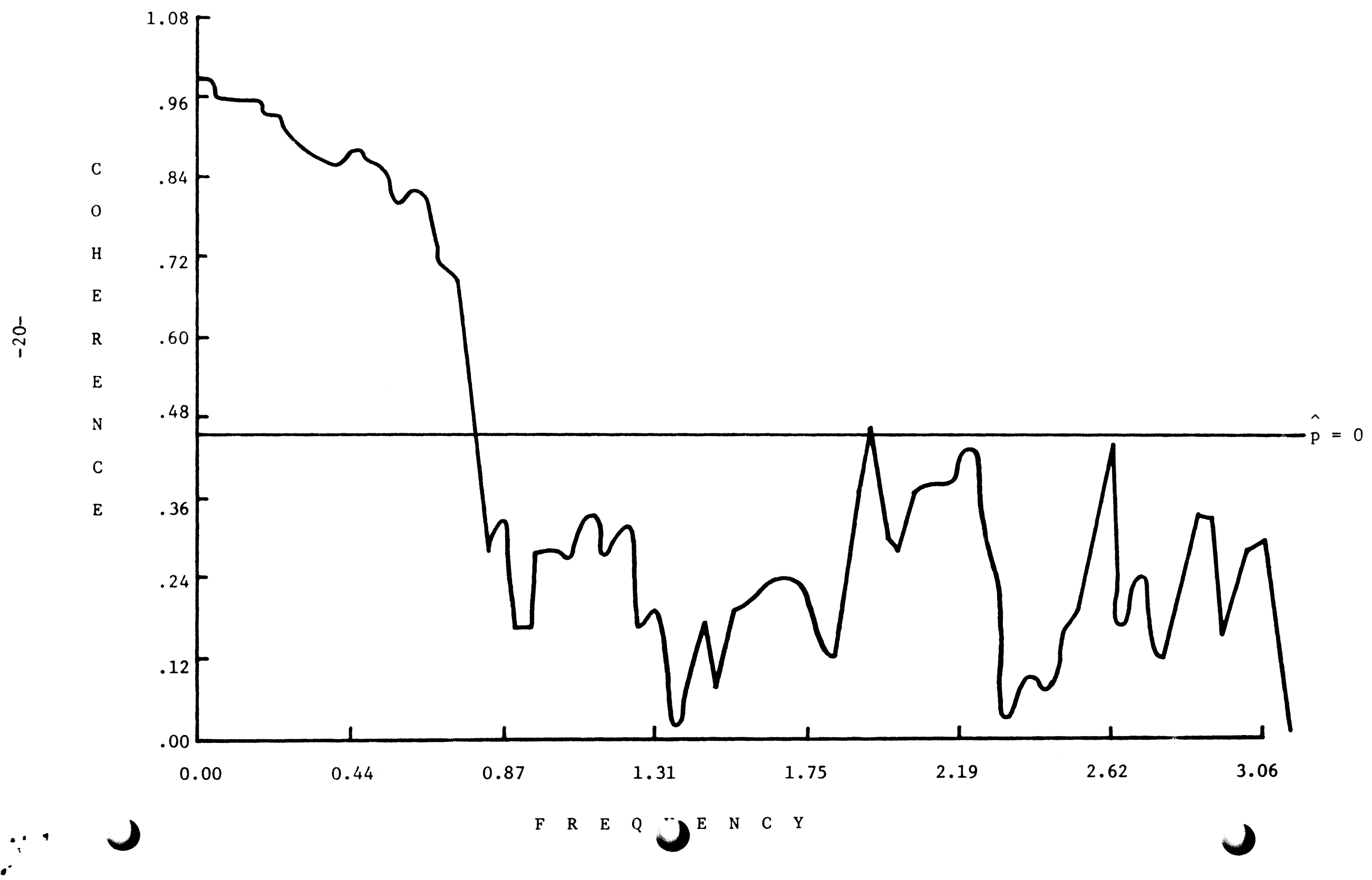


1/ One could also rely on the asymptotic independence of the spectral ordinates in the construction of this $r$-dimensional rectangle (see e.g. Just). Bonferroni's inequality, however, is easier to apply and given independence will generate an exact confidence interval. 


\section{REFERENCES}

Holbrook Working, "A Theory of Anticipatory Prices," American Economic Review XIVIII (1958) : 188-199.

J. P. Danthine, "Martingales, Market Efficiency and Commodity Prices," European Economic Review, 非10 (1977) : 79-98.

M. J. Brennan, "The Supply of Storage," American Economic Review LXVIII (1958) : 50-72.

T. M. Hammonds, The Producer's and Lender's Guide to Futures Trading, Conrad Press, Corvallis, Oregon, 1974.

L. H. Koopmans, The Spectral Analysis of Time Series, Academic Press (1974), New York.

W. G. Tomek and R. W. Gray, "Temporal Relationships Among Prices on Commodity Futures Markets: Their Allocative and Stabilizing Roles," American Journal of Agricultural Economics 52 (1970) : $372-80$.

F. H. Weymar, The Dymanics of the World Cocoa Market, MIT Press, Cambridge, Massachusetts, 1968.

Richard E. Just, "Spectral Analysis of Stochastic Properties in Regression: An Application in Supply Response Identification," American Journal of Agricultural Economics 58 (November 1978) : $712-720$. 